\title{
Matrix metalloproteinases in head and neck cancer: current perspectives
}

\author{
This article was published in the following Dove Press journal: \\ Metalloproteinases In Medicine \\ 2 May 2017 \\ Number of times this article has been viewed
}

\author{
loannis Gkouveris' \\ Nikolaos G Nikitakis ${ }^{2}$ \\ Jaya Aseervatham' \\ Nanditha Rao' \\ Kalu UE Ogbureke ${ }^{1,2}$ \\ 'Department of Oral Pathology, \\ School of Dentistry, National and \\ Kapodistrian University of Athens, \\ Athens, Greece; ${ }^{2}$ Department of \\ Diagnostic and Biomedical Sciences, \\ School of Dentistry, University of \\ Texas Health Science Center at \\ Houston, Houston, TX, USA
}

\begin{abstract}
Matrix metalloproteinases (MMPs) are zinc-dependent endopeptidases encoded by 24 distinct genes. Their functions have been implicated in numerous normal and pathologic processes, including uterine involution and organogenesis, inflammation and wound healing, vascular and autoimmune disease progression. Pertinent to this review, the role of MMPs in cancer biology is fairly well researched and documented, and remains a subject of continuing intense investigation. Not only are several MMPs overexpressed in head and neck squamous cell carcinomas (HNSCCs), expression has been correlated with salient tumorigenic hallmarks, such as cell proliferation, angiogenesis, invasion, and metastasis. The utility of changes in the expression profile, as well as various MMP polymorphisms as potential prognostic markers in oral cancers and oral premalignant lesions, have been investigated. Furthermore, the potential therapeutic utility of targeting MMPs in cancer remains attractive, although outcomes in this respect appear so far to be less encouraging with respect to HNSCCs. Because of the disappointing results observed in clinical trials where MMP-targeting regimens for HNSCCs utilized broad-spectrum small MMP catalytic site inhibitors, investigators now envision new strategies for MMP-specific targeting based on the recognition of new noncatalytic MMP domains with distinct functions. This review provides an overview of MMP activities in general and in cancers, and an update of their activities in HNSCC. Specifically, their role in the development and progression of HNSCC and their function as signaling molecules is discussed. Finally, their role as potential prognostic biomarkers and therapeutic targets in HNSCC is revisited.
\end{abstract}

Keywords: MMPs, head and neck cancers, HNSCCs, oral squamous cell carcinoma, prognosis, therapy

\section{Introduction}

Head and neck squamous cell carcinoma (HNSCC) is the sixth-most common cancer worldwide, accounting for more than 550,000 cases and approximately 300,000 deaths annually. ${ }^{1}$ HNSCCs are dominantly neoplasms arising from the squamous mucosae of the upper aerodigestive tract, accessory salivary glands, oropharynx, nasopharynx, and hypopharynx. ${ }^{2}$ The 5-year survival rate for patients with HNSCC depends on the tumor stage at the time of diagnosis, but overall is approximately $50 \%$, and has not improved significantly over the past five decades, despite advances in treatment techniques and modalities. ${ }^{3}$ The molecular basis of HNSCC has been extensively studied, and several genetic and epigenetic alterations have been characterized and associated with cancer-cell proliferation, survival, differentiation, and invasion/metastasis, in an effort to identify novel diagnostic and prognostic markers and therapeutic targets. ${ }^{2,4}$
Correspondence: Kalu UE Ogbureke School of Dentistry, University of Texas Health Science Center at Houston, 7500 Cambridge Street, Houston, TX 77054, USA

$\mathrm{Tel}+\mathrm{I} 7134864406$

$\mathrm{Fax}+\mathrm{I} 7134864416$

Email kalu.ogbureke@uth.tmc.edu 
For the most part, HNSCCs are local diseases, which may spread to regional lymph nodes, with distant metastasis often a late event with fatal outcome. ${ }^{5}$ Characteristics of malignant neoplasms in general and typical of epithelial malignant neoplasms, local, regional, or metastatic spread depend on a series of interactions and a successful breach of the epithelial-mesenchymal interface comprising the basement membrane, fibroblasts, extracellular matrix (ECM), immune cells, and vasculature. These epithelial-mesenchymal interactions involving cell-cell, cell-ECM, and angiogenesis constitute vital components in the multistep process of carcinogenesis. Notably, ECM remodeling during tumor progression is mediated by MMPs. ${ }^{6-8}$

Here, we provide an overview and update of MMP activities in cancer biology, with specific focus on their activities in HNSCCs. Their role in the development and progression of HNSCC, their function as signaling molecules, and their potential prognostic utility and continued targets for new therapeutic designs for HNSCCs are revisited. Finally, their role as potential prognostic biomarkers and therapeutic targets in HNSCC is revisited.

\section{Matrix metalloproteinases Classification of MMPs}

As summarized in Figure 1, MMPs are classified into collagenases, stromelysins, gelatinases, matrilysins, metalloelastase,

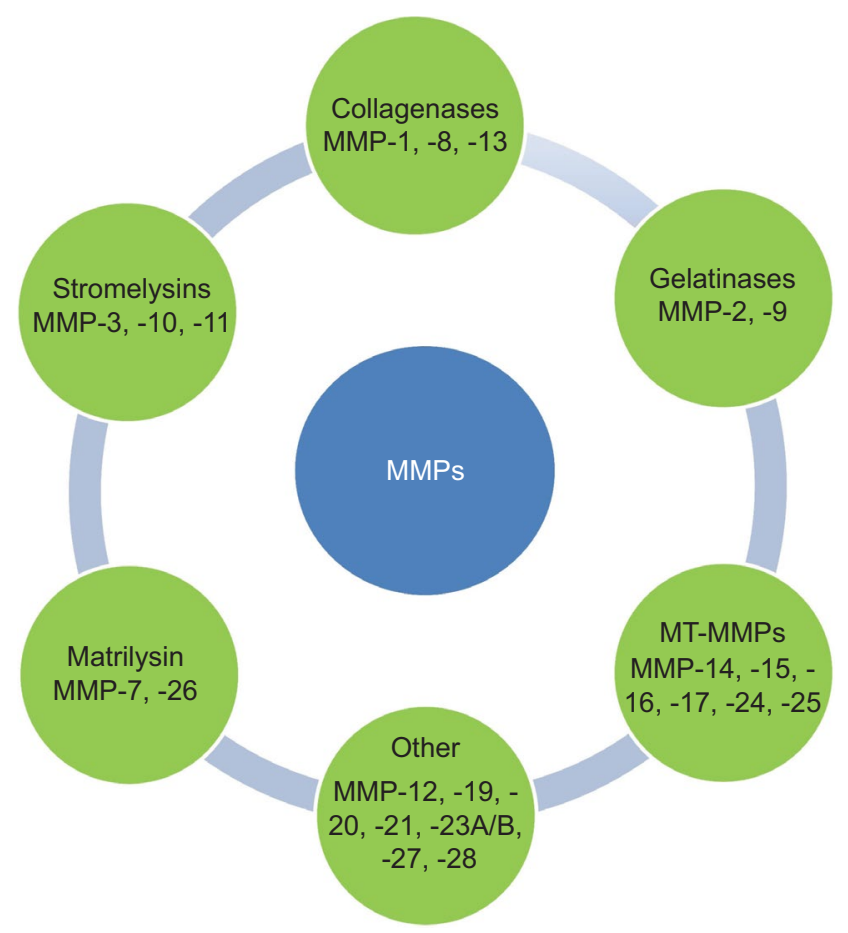

Figure I Classification of MMPs.

Abbreviations: MMPs, matrix metalloproteinases; MT, membrane-type. membrane-type MMPs, and others on the basis of their substrate specificity. ${ }^{9,10}$ Collagenases (MMP1, -8, and -13) are secreted MMPs that cleave different types of collagen at specific sites prior to degradation by other MMPs. ${ }^{11}$ Gelatinases (MMP2 and MMP9) degrade gelatin, collagens, precursors of TNF $\alpha$ and IL-1 $\beta$, elastin, proteoglycan, and fibrillin $1 .^{12}$ They are expressed by endothelial cells, osteoclasts, chondrocytes, osteoblasts, and malignant cells. MMP12 degrades elastin, type IV collagen, type I gelatin, myelin basic protein, and $\alpha_{1}$-antitrypsin. ${ }^{13}$ MMP12 is mainly expressed by macrophages, and is associated with varied pathologic conditions, including inflammation. ${ }^{13}$

The domain structure, substrate activities, and biologic functions of the membrane-type MMPs (MT-MMPs) were recently described in an elaborate and elegant review by Itoh. ${ }^{14}$ Briefly, MT-MMPs have either a transmembrane domain or a glycosylphosphatidylinositol anchor. ${ }^{14}$ MTMMPs include MMP14 (MT1-MMP), -15 (MT2-MMP), -16 (MT3-MMP), -17 (MT4-MMP), -24 (MT5-MMP), and -26 (MT6-MMP). ${ }^{14}$ Whereas MT1-, MT2-, MT3-, and MT5MMPs are secured as transmembrane domains, MT4-MMP and MT6-MMP are anchored to the cell membrane via a glycosylphosphatidylinositol anchor. ${ }^{14}$ Pro-MT-MMPs are activated by proprotein convertases, such as furin. ${ }^{14}$ With respect to their substrate activities, MT1-MMP demonstrates an extensive substrate of targets that include the degradation of fibrillary collagens: types I, II, and III (but not type IV) collagens. ${ }^{14}$ While other MT-MMPs exhibit varying degrees of collagenolysis and specificity, only MT1-MMP degrades fibrillary collagen. ${ }^{14}$ MT1-, MT2-, MT3-, and MT5-MMPs activate pro-MMP2 on the cell surface and degrade laminin and fibronectin. ${ }^{14}$ The degradation of fibrin by MT1-, MT2-, and MT3-MMPs has been shown to promote cellular invasion into matrices, ${ }^{15-17}$ a process that may promote cancer-cell activity.

MMP20 (enamelysin), first cloned from odontoblasts, was until recently widely regarded as tooth-specific. ${ }^{18-22}$ It is a proteolytic enzyme critical for proper dental enamel formation. ${ }^{18-22}$ Recently, we reported the expression of MMP20 in oral squamous cell carcinomas (OSCCs) and metabolically active duct epithelial systems of the salivary gland and nephron, indicating that the tissue distribution of MMP20 under physiologic and pathologic conditions may be wider than previously thought. ${ }^{22-24}$

On the basis of mechanism of regulation, MMPs are classified into three groups: group 1 (MMP1, -3, -7, -9, -12, -19, and -26) contains a TATA box and an activator protein, AP1, which binds to the Fos and Jun family of transcription factors; 
group 2 MMPs (MMP8, -11, and -21) have the TATA box, but lack the AP1 site; and group 3 MMPs have neither the TATA box nor the AP1 site. ${ }^{25}$ Notwithstanding the presence or absence of TATA box or AP1 site, all MMPs are regulated by various factors. MMP activity may be induced by cytokines, growth factors, and oncogenes. Signal-transduction pathways, such as MAPKs (eg, ERK1 and ERK2) can inhibit or stimulate the transcription of MMPs. ${ }^{26}$ The ETS family, ${ }^{27}$ $\mathrm{NF \kappa B},{ }^{28} \mathrm{STATs},{ }^{11} \mathrm{CIZ}$, and $\mathrm{p} 53^{29}$ serve as positive modulators, while TGF $\beta$-inhibitory elements or AG-rich elements serve as negative modulators of MMP transcription. ${ }^{30,31}$

\section{Structure of MMPs}

MMPs are zinc metalloenzymes and encoded by at least 26 distinct genes. ${ }^{6-8}$ Although structural similarity exists among members of the MMP family, subtle but significant differences have been identified. As summarized in Figure 2, all MMPs have the propeptide (prodomain) region responsible for maintaining the latency of the inactive enzyme. This is followed by a catalytic domain harboring the zinc $\left(\mathrm{Zn}^{2+}\right)$ active site that binds to three histidine residues and a conserved methionine, and the hemopexin-like C-terminal domain linked to the catalytic domain by a hinge region..$^{32,33}$ The latter domain determines the substrate specificity and interactions with inhibitors. ${ }^{34}$ Activation of MMPs takes place in the pericellular space with the involvement of integrins (eg, pro-MMP2) or it may happen intracellularly with furin-like proprotein convertases (eg, MT-MMPs), cleaving the prodomain from the catalytic domain, thereby rendering MMPs active. ${ }^{35}$

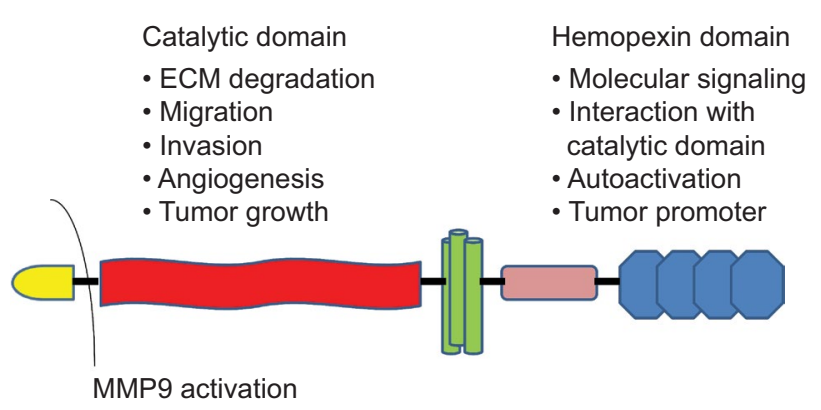

\footnotetext{
$\begin{array}{ll}\square & \text { Prodomain } \\ \text { Catalytic domain } \\ \square \text { Fibronectin-like domain } \\ \square & \text { Linker } \\ \square & \text { Hemopexin domain }\end{array}$
}

Figure 2 Structure of MMPs.

Notes: Schematics of MMP9 structure, showing the various domains common to all MMPs. Differences however exist among members of the MMP family.

Abbreviations: MMPs, matrix metalloproteinases; ECM, extracellular matrix.

\section{SIBLINGs as activators of MMPs}

A universal classic dogma of latent MMP activation usually entails a cleaving of the propeptide as a necessary step to MMP enzymatic activation. In 2004, Fedarko et al ${ }^{36}$ reported that three members of the SIBLING family - BSP, DMP1, and OPN - bind and activate three specific MMPs in vitro: BSP-MMP2, DMP1-MMP9, and OPN-MMP3. The other two members of the SIBLING family are DSPP and MEPE. ${ }^{37}$ Although the cognate MMP partner for MEPE, if any, is yet to be identified, we recently identified MMP20 as the cognate MMP for DSPP. ${ }^{22-24}$

As depicted in Figure 3, this activation is significant, because the bound SIBLINGs activate their cognate MMP partners, not by removing the inhibitory propeptides, but by inducing a conformational change that lowers the propeptides' affinity for their own binding domain. ${ }^{36}$ In consequence, the propeptides vacate the active sites, thereby allowing substrates to be digested (Figure 3A). While the resultant SIBLING-pro-MMP pairs exhibit resistance to the inhibitory activities of TIMPs, activated MMPs previously inhibited by TIMPs become reactivated upon binding of their cognate MMP partner (Figure 3B). ${ }^{36}$ The check and balance necessary for reversing these activation pathways are provided by circulating complement factor $\mathrm{H}$, which has a much higher affinity ( 100-fold) for BSP, DMP1, and OPN than the SIBLINGs have for their cognate MMP partners. ${ }^{36}$ Therefore, complement factor $\mathrm{H}$ binds to SIBLINGs on the active and latent (Figure 3C) MMPs, in order to disengage them from the protease complex, allowing the propeptide and TIMP to reinhibit protease activity (Figure 3D).

Subsequent studies showed that the SIBLING-MMP pairing observed in vitro also obtains in vivo, suggesting that SIBLING-MMP interaction may be biologically important. ${ }^{22-24}$ Published results from our laboratory show SIBLINGs with known MMP partners coexpressing and colocalizing with their cognate MMP partners in highly metabolic duct epithelial systems of the salivary gland and nephron, and in OSCC cells (DSPP-MMP20 in Figure 3E). ${ }^{22-24}$

\section{MMPs and cancer}

Cancer research has traditionally highlighted the role of overexpressed molecules that contribute to the survival and proliferation of cancer cells. At the same time, several studies have presented compelling evidence that the tumor microenvironment, particularly that of the ECM, plays a crucial role in cancer progression. ${ }^{33}$ In this context, the role of MMPs in ECM remodeling, cancer invasion, angiogenesis, and metastasis has been investigated and continues to be so. ${ }^{7}$ The expression/ 

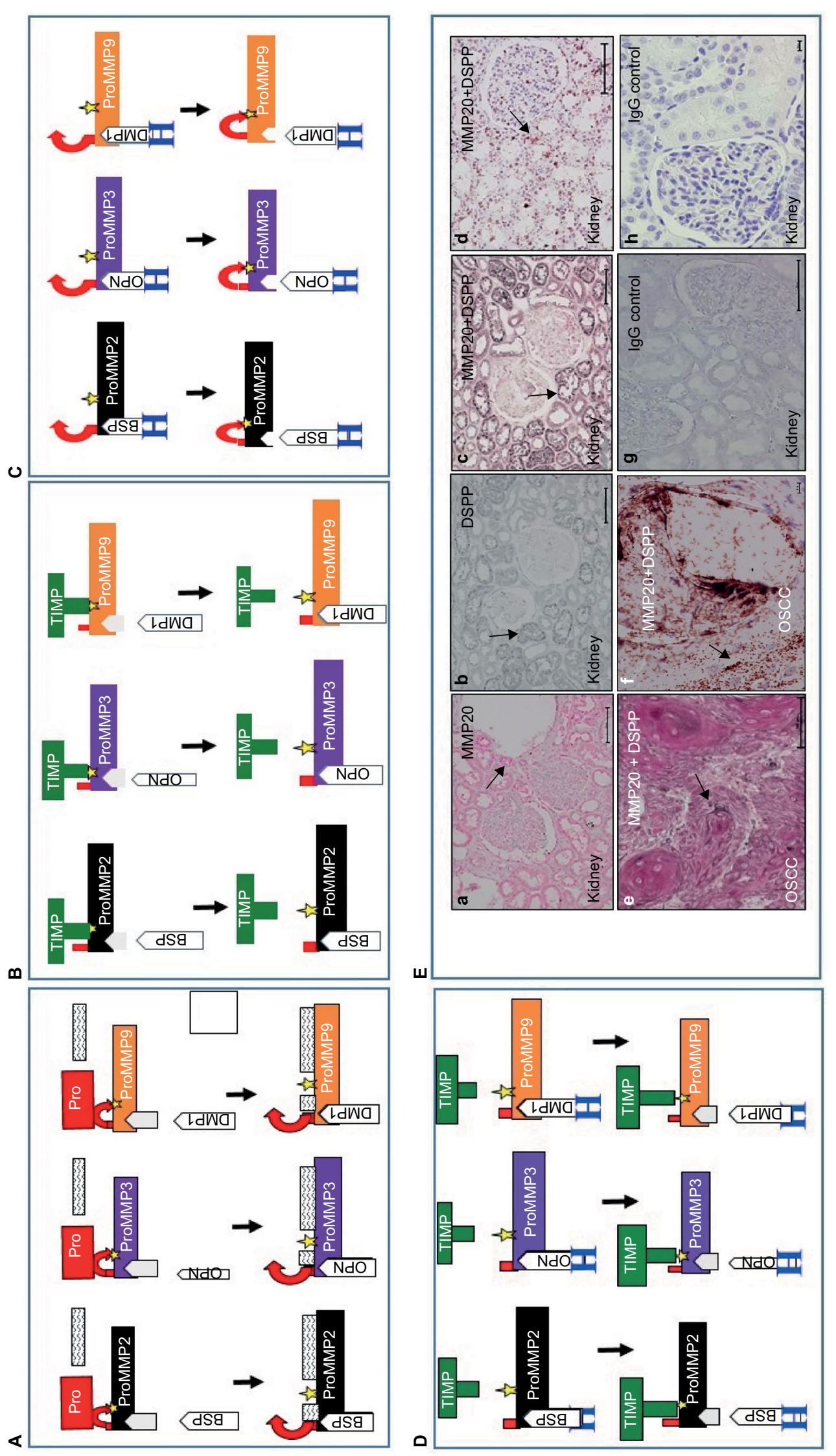

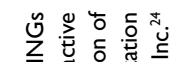

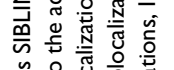

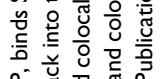

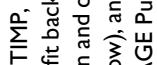

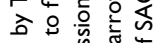

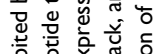

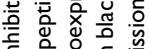

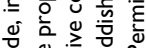

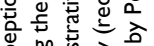

응

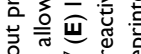

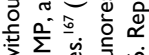

उ $\sum_{\Sigma}$

位表方

鱼它总品

है

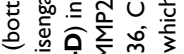

可过的

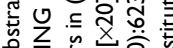

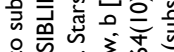

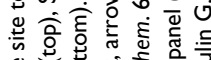

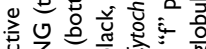

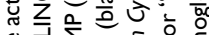

㕸

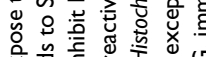

ช

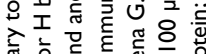

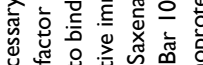

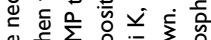

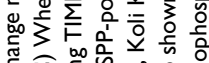

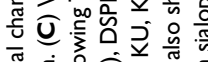

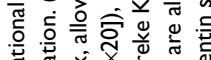

중

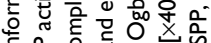

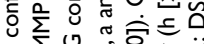

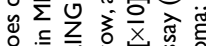

品品

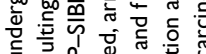

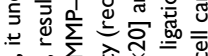

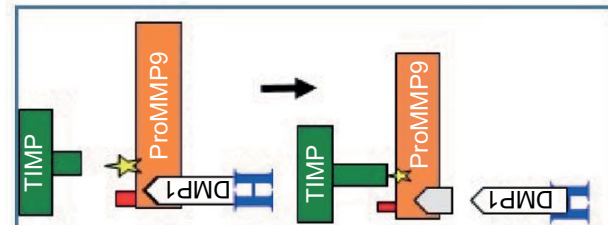

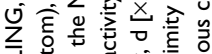

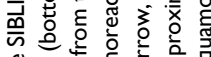

罗娄 U

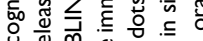

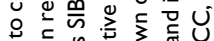

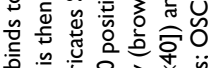

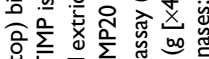

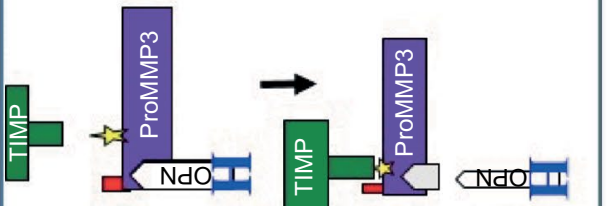

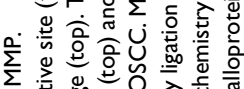

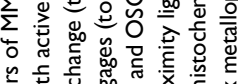

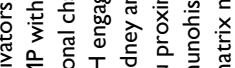

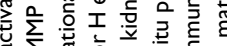

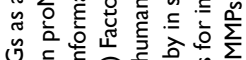

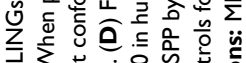

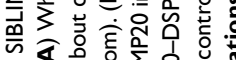

m 400

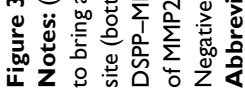


upregulation of specific MMPs, including MMP1, -2, -7, -9, and -13 , in several human cancers has been demonstrated, with expression/upregulation correlated with tumor aggression, tumor stage, and poor patient prognosis. ${ }^{33,34}$ It stands to reason, therefore, that they have been proposed as potential diagnostic and prognostic biomarkers in many types of cancer, ${ }^{6}$ with research efforts intensifying toward establishing any diagnostic and prognostic values of clinical importance. In addition, a growing number of therapeutic anticancer strategies continue to focus on MMPs as attractive targets. ${ }^{6,34,35,38}$

Currently, it is fairly well established that polymorphisms in MMP genes are associated with progression of a number of cancers. For example, meta-analysis revealed the $M M P 7^{-181 \mathrm{~A} / \mathrm{G}}$ polymorphism as a low-penetrant risk factor for cancer development in the East Asian population. ${ }^{39}$ $M M P$ 2-promoter polymorphism has been associated with invasive cervical carcinoma in Mexican women. ${ }^{40}$ Furthermore, polymorphisms in $M M P 2$ in nonsmokers, and $M M P 12$ and MMP13 in smokers, have been linked to gastric cardia adenocarcinoma in a high-incidence region of north China. ${ }^{41}$ In a large meta-analysis, Peng et al found that $M M P 2$ $(-1306 \mathrm{C}>\mathrm{T}$ and $-735 \mathrm{C}>\mathrm{T})$ and $M M P 7^{-181 \mathrm{~A}>\mathrm{G}}$ polymorphisms play allele-specific roles in cancer development, while the $M M P 9^{-1562 \mathrm{C}>\mathrm{T}}$ polymorphism did not appear to be a major risk factor for cancer. ${ }^{42}$ Another meta-analysis by Li et al, ${ }^{43}$ focusing on digestive tract cancers, demonstrated an association of polymorphisms in the promoter regions of specific MMPs with increased (MMP1 and -7) or decreased (MMP2 and -9) susceptibility, while Yang et $\mathrm{al}^{44}$ further suggested that the $M M P 7^{-181 \mathrm{~A}>\mathrm{G}}$ polymorphism may contribute to susceptibility to gastric cancer. In their meta-analysis of studies investigating the role of the $-1171(5 \mathrm{~A}>6 \mathrm{~A})$ polymorphism in the promoter region of $M M P 3$, Yang et $\mathrm{al}^{45}$ did not find an association with overall cancer risk, suggesting that this polymorphism may be related to a decreased cancer risk in general in Asian populations when specifically compared with gastrointestinal cancers. ${ }^{45}$

\section{MMPs in cancer invasion and metastasis}

Invasion is a localized process that occurs at the tumor-host interface, where tumor and stromal cells exchange biologic molecules (enzymes and cytokines) that modulate the local ECM and stimulate cell migration. The invasive front consists of a unique subset of tumor cells interfacing with bone marrow-derived and organ-specific supportive cells. During invasion, MMPs modulate the availability of growth factors and cell-surface receptors, while driving the formation of specialized structures called invadopodia. Invadopodia utilize several secreted and activated MMPs to degrade ECM macromolecules, modulate shedding of membrane-anchored ligands (eg, epidermal growth factor receptor [EGFR]), control integrin-proliferation effects, alter antiapoptotic signals by cleaving Fas ligands, and regulate tumor vasculature. ${ }^{6} \mathrm{MMPs}$ also may dampen chemotactic and inflammatory responses by inactivating MCP $3 .{ }^{46}$ Therefore, MMPs not only aid in cell invasion but also in many cases may inhibit invasion, depending on a balance of factors expressed. For example, T cells and macrophages produce the TNF $\alpha$-related cytokine RANKL, which interacts with its receptor and activates IKK $\alpha .{ }^{47} \mathrm{IKK} \alpha$ inhibits tumor progression by the expression of maspin. Maspin in turn alters the expression of integrin-adhesion molecules restricting cell mobility. ${ }^{47}$ Metastasis, a major cause of death in cancer, is a multistep process that involves the stroma, blood vessels, and other associated factors. Successful tumor metastasis depends on several parameters, such as cell invasion, migration, angiogenesis, host immune escape, and extravasation. In all, MMPs are overt or covert crucial players in several of these metastatic processes. ${ }^{48}$

\section{MMPs in HNSCC MMP-expression profile in HNSCCs}

Several published studies have demonstrated that certain MMPs are upregulated in HNSCC, and elucidated their role in multiple aspects of tumor formation and progression. ${ }^{49}$ MMP1, -2, -3, -7, -8, -9, -10, -11, -13, and -14 are most commonly noted to be overexpressed in head and neck cancers. ${ }^{50}$ Specifically, gene microarray-expression analysis in whole HNSCC-tumor samples detected overexpression of MMP1, -2 , and $-3,{ }^{11,52}$ whereas another comprehensive review indicated that MMP1, $-3,-7,-10,-12$, and -13 expressions were significantly increased in almost all investigated microarray data sets of HNSCC. ${ }^{49}$ Immunohistochemical studies have also confirmed the results of microarray analysis. For example, Ye et $\mathrm{al}^{53}$ detected upregulated expression of MMP1, $-3,-7,-9,-10$, $-11,-12$, and -13 in tongue squamous cell carcinoma (SCC).

Omar et $\mathrm{al}^{54}$ reported higher MMP7-expression levels in the invasive portion of oral and cutaneous SCCs that was more intense in oral tumors, and without MMP8 expression in either cancer type. Ogbureke et $\mathrm{al}^{55}$ reported that BSP and OPN are overexpressed in OSCCs, accompanied by their known cognate MMP partners: MMP2 and MMP3, respectively. Recently, Saxena et $\mathrm{al}^{22}$ reported the expression of MMP20 in OSCCs and dysplastic oral premalignant lesions using archived human tissues and cell lines. Hitherto this report, MMP20 expression had been widely regarded as tooth-specific, and thus temporally limited to the odontogenic 
apparatus during odontogenesis, where it participates with MMP2 in processing DSPP into DSP, DPP, and DGP. ${ }^{22,56}$

MMPs are elaborated by malignant epithelial cells, as well as cells of the surrounding stroma, including endothelial cells, fibroblasts, and inflammatory cells ${ }^{57}$ As a result, many studies have examined MMP-expression levels in body fluid, notably serum, as potential diagnostic and prognostic indicators in HNSCC. Lotfi et $\mathrm{al}^{58}$ indicated that serum levels of MMP2 and MMP9 were higher in OSCC patients compared with levels in healthy subjects. Tadbir et al ${ }^{59}$ reported high MMP3 serum levels in patients with OSCC, and suggested that MMP3 serum concentration may aid diagnosis, but not to predict prognosis in OSCC. Elevated serum levels of MMP2 and MMP9, along with TGF $\beta_{1}$, E-selectin, and CRP, have been reported in patients with leukoplakia. ${ }^{60}$

\section{MMP polymorphisms in HNSCCs}

Genetic studies have reported that MMP single-nucleotide gene polymorphisms in the promoter regions of MMP1, -2, -3 , and -9 are associated with OSCC. ${ }^{61,62}$ In another study, by Chaudhary et al, the authors detected a higher frequency of MMP1-promoter genotypes with the $2 \mathrm{G}$ allele, which is associated with higher enzymatic activity, in patients with HNSCC or the preneoplastic condition, oral submucous fibrosis. ${ }^{63}$ In addition, elevated expression of the $5 \mathrm{~A}$ allele of the $M M P 3$ gene has been associated with an increased risk of oral SCC development. ${ }^{64}$ It has also been reported that the $M M P 9^{\mathrm{P} 574 \mathrm{R}}$ polymorphism (GG genotype) may contain a genetic risk factor for esophageal $\mathrm{SCC},{ }^{65}$ and the $\mathrm{C}>\mathrm{T}$ polymorphism in the MMP9 promoter is associated with the risk of developing OSCC. ${ }^{66,67}$ On the other hand, Lin et $\mathrm{al}^{68}$ demonstrated that the $-1306 \mathrm{C}>\mathrm{T}$ polymorphism in the MMP2 promoter, which eliminates the Sp1-binding site and downregulates the expression of the $M M P 2$ gene, is associated with a decreased susceptibility for developing OSCC. In consequence, patients carrying the $\mathrm{CC}$ genotype had almost twice the risk compared with the CT or TT genotype. ${ }^{69}$

\section{MMPs in HNSCC invasion}

The activities of several proteases, particularly MMPs, have been implicated in HNSCC invasion. ${ }^{50} \mathrm{AP} 1$ has been reported to increase the transcription of MMP9,${ }^{69,70}$ while EGFR and integrins enhance MMP9 activity. ${ }^{71-75}$ Furthermore, MMP9 degrades type IV collagen and promotes HNSCC invasion. ${ }^{76,77}$ Indeed, immunohistochemical studies correlated MMP expression with loss of type IV collagen $\alpha$-chain areas in OSCC, and MMP9 has been proposed as an invasion- and infiltration-pattern marker of OSCC at the invasive front. ${ }^{78}$
MMP9 is able to cleave several proteins including TGF $\beta$ and chemokines, E-cadherin, and certain cell-surface receptors. ${ }^{79,80}$ MMP2 and MT1-MMP have also been implicated in HNSCC invasion. ${ }^{81}$ Moreover, MT1-MMP, along with TIMP2, has been shown to contribute to secreted protease activation, such as MMP2. ${ }^{82,83}$ In addition, EMMPRIN is another protein that has been proposed to increase the protease activity of MMPs, cathepsin B, and UPAR, in order to enhance HNSCC invasion. ${ }^{72,84}$ In concert with other players, MMP10 and MMP13 have been associated with HNSCC invasion. ${ }^{85-89}$

\section{MMPs and angiogenesis}

MMPs play a key role in ECM remodeling. In addition, they release growth factors and unmask cryptic sites, which help malignant cells to elude homeostatic control. ${ }^{90}$ For example, following activation by plasmin, MMPs bind to docking sites on cell surfaces. Plasmin activates MMP2 and MMP9, and multiple MT-MMPs process the pro-MMP2 to its active form. ${ }^{77}$ Activated MMP9 induces angiogenic switch, increases the availability of growth factors, and plays an important role in recruiting pericytes from the bone marrow. It also converts the Kit ligand from a membrane-bound molecule to a soluble survival/mitogenic factor soluble Kit ligand and promotes tumor angiogenesis through the release of ECM-bound angiogenic factors, such as VEGF. ${ }^{91}$ MMP2, -3 , and -7 induce the release of TGF $\beta_{1}$ from decorin, a proteoglycan that sequesters TGF $\beta$ in the matrix. ${ }^{92} \mathrm{CD} 44$ and $\alpha_{\mathrm{v}} \beta_{3}$ localize MMP2 and -9 to the migrating invasive front and provide a docking site for the proteinases. ${ }^{93}$

Collagen remodeling in perivascular stroma is associated with angiogenesis. The first step in endothelial morphogenesis is the cleavage of type IV collagen of the basement membrane by MMP2 and -9 in vivo (as well as MMP1 in vitro). MT1-MMP breaks down collagen types I-III, gelatin, laminin, and other ECM components, in addition to activating pro-MMP2. ${ }^{94}$ Collagen cross-linking induces tumor progression by activating FAK, PI3K, and Akt. ${ }^{95}$ MMP1 induces epidermal hyperplasia and increases the susceptibility to tumorigenesis, invasion, and angiogenesis. ${ }^{49}$ Since MMP3 is expressed by fibroblasts and tumor cells, it regulates cancer stem cells during tumor initiation and metastasis. ${ }^{90}$

\section{MMPs and angiogenesis in HNSCC}

MMPs are upregulated by Notch1, EGFR, TGF $\beta$, HGF, and GM-CSF, which are commonly overexpressed in HNSCC. 
MMP7 expressed in OSCC of the buccal mucosa is mostly affected by PTEN mutation. ${ }^{96}$ It also enhances endothelial cell proliferation and upregulates expression of MMP1 and -2. ${ }^{97}$ MMP10 plays an important role in the invasion and metastasis of HNSCC, and is associated with p38 MAPK inhibition. ${ }^{98}$ Epithelial dedifferentiation and histologic aggression, extracapsular spread, and nodal metastasis of HNSCCs are associated with MMP12 expression. ${ }^{99}$ Invasive cells that express periostin, IFITM1, and Wnt5b induce MMP10 and -13 expression.

MMP13 produced from stromal fibroblasts promotes angiogenesis and aggression of HNSCC through increased secretion of VEGFA and VEGF-2 from fibroblasts and endothelial cells, also activating latent MMP9. ${ }^{49}$ MMP19, found in the tumor-invasive fronts, facilitates HNSCC invasiveness. ${ }^{100}$ MT1-MMP regulates VEGF expression and activates the Akt and mTOR pathways. It also stimulates cell migration through a nonproteolytic mechanism, involving MEK1/2-ERK1/2-p90RSK signaling. ${ }^{101}$ MMP14 facilitates endothelial migration by shedding Tie2. ${ }^{102}$ It also activates pro-MMP13 by cleaving the signal peptide. ${ }^{102}$ MT4-MMP increases metastatic intravasation by increasing vascular leakage. ${ }^{92}$

\section{MMPs as signaling molecules Noncatalytic functions}

Prior to recent understandings and updates on the relevance of minute structural difference in the various MMPs to function, studies focused on the catalytic role of MMPs in many important physiological and pathological processes. ${ }^{103}$ It is well understood that the MMP-family structure includes a hydrophobic signal peptide, a propeptide domain for enzyme latency, a catalytic domain, and a hemopexin-like C-terminal domain, hemopexin (PEX), connected to the catalytic region via a flexible hinge domain. ${ }^{80}$ Indeed, the majority of MMPs, excluding the smaller matrilysins MMP7, -23, and -26, have a COOH-terminal PEX domain with a distinct four-bladed $\beta$-propeller structure. ${ }^{104}$ The PEX domain of MMPs is now considered to be responsible for their noncatalytic activity, as it is capable of interacting with receptors, inhibitors, and substrates. ${ }^{105-107}$ For example, the PEX domain interacts with cellsurface receptors, including LRP1 and megalin/LRP2, ${ }^{108,109}$ as well as with inhibitors, such as TIMP1 ${ }^{110}$ and TIMP3. ${ }^{111}$ Besides receptor and inhibitor binding, the PEX region also interacts with substrates, including gelatin, collagen types I and IV, elastin, and fibrinogen. ${ }^{112,113}$ Recently, it has been proposed that the PEX domain is involved in autoactivation, by guiding the activation of the MMP catalytic domain. ${ }^{104}$
Although published data on the tumorigenic contribution of noncatalytic functions of MMPs are not derived from head and neck cancer cases, these studies of cancers of other regions implicate MMPs that also are highly expressed in HNSCC. The hemopexin domains of MMP9 (PEX9) have been extensively studied. Sequence-alignment studies of human MMP9 revealed that its PEX9 domain shows low homology with other MMP PEX domains (25\%-30\% amino acid identity), thereby suggesting PEX9 as a potential therapeutic target for selective MMP9 inhibition. ${ }^{114,115}$ Ugarte-Berzal et al also have shown that although MMP9 degrades gelatin, the PEX9 domain inhibits this degradation by shielding gelatin and averting its interaction with the MMP9 catalytic site. ${ }^{14,115}$ The PEX9 domain may regulate intracellular signaling and survival in chronic lymphocytic leukemia (CLL) cells. ${ }^{114,115}$ Ugarte-Berzal et al reported that the PEX9 domain contributes to CLL progression, and found a connection between blade B4 and the $\alpha_{4} \beta_{1}$ integrin. ${ }^{14,115}$ These authors recently proposed a novel PEX9 sequence involved in CLL PEX9-pro-MMP9 binding and interaction with CD44. ${ }^{115}$

In other relevant studies, pro-MMP9 was shown to bind with the $\mathrm{Ku}$ protein through its PEX domain to promote the migration of acute myeloid leukemia cells, ${ }^{116}$ whereas PEX9 and CD44 interaction in COS1 monkey kidney cells induced cell migration. ${ }^{117}$ Furthermore, thrombin-mediated invasion of U2 osteosarcoma cells involved a PEX9 and $\beta_{1}$-integrin association, ${ }^{118}$ while MMP9 catalytic and PEX domains have been reported to induce FGF2-mediated angiogenesis in neutrophils. ${ }^{119}$

With respect to other MMPs, Suenaga et al ${ }^{120}$ reported that binding of CD44 to the MMP14 PEX domain is critical for shedding of human fibrosarcoma and breast carcinoma cells. In addition, Eisenach et al described an MMP14-VEGFR2Src complex formation that controls VEGFR2 cell-surface localization through hemopexin-dependent activity in breast cancer cells. ${ }^{121}$ As a result of this complex formation, Akt and mTOR are activated, leading to enhanced VEGFA transcription. ${ }^{121}$ Cross-talk signaling between MMP14 and CD44 has also been proposed for phosphorylation of the EGF receptor, leading to the activation of the MAPK and PI3K signaling cascade and consequent migration of Cos 1 cells. ${ }^{122}$

The MMP3 PEX domain has been found to induce hyperplastic growth in orthotopic transplants of lentivirally transduced mammary epithelial cells, even in the complete absence of its active domain, resulting in a nonproteolytic interaction with the Wnt ligand. ${ }^{104}$ A similar function of MMP3 PEX has also been suggested to enhance invasiveness 
of breast cancer cells. ${ }^{123}$ Extracellular interaction of MMP3 PEX with HSP90 $\beta$ has been reported to be critical for invasion and morphogenesis of mouse mammary epithelial cells. ${ }^{123}$ Furthermore, extracellular Hsp $90 \alpha$ stabilizes and protects MMP2 from degradation in human breast cancer cells through a regulatory mechanism mediated by interaction of Hsp90 $\alpha$ with the MMP2 C-terminal hemopexin domain. ${ }^{124}$ This interaction enhances the proteolytic activity of MMP2, and thus promotes tumor angiogenesis.

MMP23 contains a noncatalytic region different from hemopexin. This region presents a small toxin-like domain and an immunoglobulin-like cell-adhesion molecule domain. These two domains were found to interact with potassium channels in the endoplasmic reticulum. Notably, MMP23 and potassium-channel coexpression has been reported in several diseases, including cancer and inflammatory disorders. ${ }^{125}$

In summary, findings of a new hemopexin-dependent role for MMPs have shifted the focus from their proteolytic activity, and added a new dimension in the role of MMPs as drug targets and a novel direction for therapeutic strategies aimed at interfering with MMP function in cancer.

\section{MMPs as tumor biomarkers}

The detection of MMPs in HNSCC tissues by such techniques as immunohistochemistry, DNA/RNA analysis, and zymography has prompted analysis of potential diagnostic and prognostic significance of MMP expression in HNSCCs. However, cautionary notes, informed by inherent limitation with these techniques, temper the outcomes of these analysis. In gene-expression studies, for example, the detected MMP-transcription levels may not reflect the biological active protein levels. Therefore, while immunohistochemical techniques may provide information on protein-expression levels of active MMPs in the tissues, antibody-antigen crossreactivity and/or interactions with latent or inhibited enzyme complexes may lead to false positives or exaggerated positive immunostain results. ${ }^{91}$ Advances in antibody technology, resulting in the production of highly specific and sensitive antibodies, are however greatly mitigating this challenge.

For the most part, reports tend to suggest that the bulk of MMPs in the tumor environment are produced by the surrounding stroma cells, and tumors may be exposed to circulating MMPs in normal serum. ${ }^{57}$ Furthermore, it is difficult to draw assertive conclusions on the significance of positive MMP immunostains based on meta-analysis, because of the heterogeneity of both data collection and statistical methods employed. Standardization of staining procedures and evaluation protocols does help to compare the variability of published data and extract valid results. ${ }^{126}$ Nevertheless, the existence of a considerable number of conflicting studies should be acknowledged, as well as the possibility that some studies indicating negative MMP expression in tumors are unlikely to be published. ${ }^{50}$

In spite of these limitations, results of several studies evaluating MMP expression in HNSCCs provide insight into their prognostic importance. The results of MMP geneexpression profiling recently carried out by lizuka et al suggested that MMP1, $-3,-7,-10,-12$, and -13 expressions are significant prognostic markers for HNSCC tumorigenicity and malignant progression. ${ }^{49}$ Earlier studies by Rosenthal and Matrisian proposed that MMP1, $-2,-9$, and -14 expression in HNSCC were related to disease progression. ${ }^{50}$ Lotfi et $\mathrm{al}^{58}$ investigated MMP2 and MMP9 serum levels in OSCC patients, and concluded that both were significantly elevated in OSCC patients compared with their healthy counterparts. Significantly, the authors considered MMP2 a better marker for assessing lymph-node metastasis and tumor grade. ${ }^{58} \mathrm{~A}$ meta-analysis of laryngeal cancers demonstrated that MMP2 expression was higher in cases with lymph-node metastasis, and suggested that upregulation of MMP2 could be instrumental in tumorigenesis, progression, and prognosis in laryngeal cancer. ${ }^{127}$

Zhang et al investigated MMP2, -3 , and -9 single-nucleotide polymorphisms in esophageal SCC. ${ }^{128}$ The authors suggested that $M M P 2^{-1306 \mathrm{TT}}$ and $M M P 9^{-1562 \mathrm{CC}}$ single-nucleotide polymorphisms correlated with increased esophageal SCC risk and significantly high death odds. ${ }^{128}$ In a study by Virós et al, ${ }^{129}$ the prognostic value of MMP2- and -9-expression levels in patients with HNSCC following treatment with radiotherapy or chemotherapy was analyzed by multivariate analysis. The authors determined that MMP9 expression was the only significant factor related to adjusted survival. ${ }^{129}$ Patients with low and high MMP9-expression levels had 5-year survival rates of $92.9 \%$ and $61 \%$, respectively. Significantly, patients with elevated MMP9 expression had a 6.1-fold higher death risk compared with patients with low MMP9 expression. The authors thus suggested that elevated MMP9 is associated with poor local disease control, and that increased MMP9 mRNA levels may represent a treatment-response marker in chemotherapy and/or radiotherapy in HNSCC patients. ${ }^{129}$

In an analysis of histologically negative surgical margins of OSCC, Ogbureke et al suggested MMP9 as a preferred predictor of tumor recurrence at histologically negative resection margins of primary OSCC. ${ }^{130}$ The authors recommended a redefinition of true-negative (tumor-free) margins in OSCC to incorporate the MMP9 status of histologically negative margins. ${ }^{130}$ It has also been reported that the immunoexpression of VEGFR2 and MMP9 in oral dysplastic lesions correlated 
with the degree of dysplasia, and appeared to be higher in more severe dysplasias. ${ }^{131}$ Furthermore, Smith et al ${ }^{132}$ noted that MMP9 may serve as a marker for increased risk of transition from oral dysplasia to frank OSCC. Similarly, Chang et $\mathrm{l}^{60}$ proposed MMP9 expression as the most relevant index of progression from leukoplakia to cancer, and suggested that physicians take into account elevated MMP9 levels in deciding treatment modality in any given case and frequency of patient follow-up.

Zhou et al $^{133}$ proposed serum autoantibody levels of MMP7 as a diagnostic biomarker for esophageal SCC. MMP7 was also found to mediate metastasis in laryngeal carcinoma. ${ }^{134}$ Elevated MMP7 levels have also been associated with negative survival in patients with OSCC. ${ }^{135}$ However, in their immunohistochemical analysis of expression levels of MMP7, -8, and -9 in OSCC and cutaneous SCCs, Omar et $\mathrm{al}^{54}$ did not find any association of MMP levels with overall survival rates.

Mäkinen et al ${ }^{136}$ investigated the potential prognostic values of MMP2, $-8,-9$, and -13 in OSCC of the tongue. MMP8 levels, though elevated and previously suggested to play a protective role in tongue OSCC, ${ }^{137}$ did not correlate with protection from tongue OSCC. ${ }^{136}$ Similarly, there was no correlation between MMP2 and -9 levels with known clinicopathologic and/or prognostic variables. ${ }^{136}$ On the other hand, the authors showed that high nuclear MMP13 expression was associated with increased invasion depth, tumor size, and poor survival in tongue OSCC. ${ }^{136}$ The authors thus suggested that elevated serum levels of MMP13 may serve as a tumor biomarker in HNSCC. ${ }^{136}$ In contrast, MMP13 was not shown to correlate with tumor recurrence in HNSCC cases. ${ }^{138}$

In summary, there is accumulating evidence that specific MMPs can serve as potential prognostic markers in HNSCC. However, conflicting data and results attributable to finesse and other variabilities associated with experimental procedures employed and statistical analytic methods remain significant confounding factors in the interpretation of results. In addition, HNSCCs are a notoriously heterogeneous population, wherein tumor behavior is intricately related to specific sites as much as it is related to biologic molecules (such as MMPs) that may be expressed at that site.

\section{Therapeutic approaches in targeting MMPs in HNSCC}

With increasing understanding of the biology of MMPs, therapeutic targeting of MMPs remains a very attractive strategy for the treatment of many cancer types, including
HNSCCs. Although early concepts and designs of biomimetic targeting of MMPs in cancers held lofty promise, disappointment with patient outcomes following clinical trial treatments soon followed. ${ }^{38,91}$ The failure (or modest success) of early anti-MMP drugs for cancers is at least in part attributable to hitherto-limited understanding of the structural diversity of MMPs and the significance of this diversity to the working of different MMPs. As summarized in Figure 4, anti-MMP drug-design strategies largely aim for interference with either catalytic or noncatalytic MMP activity.

\section{Targeting MMP catalytic activity}

Early drug research on MMP inhibitors (MMPIs) targeted binding to the MMP catalytic domain. ${ }^{38}$ MMPIs used in head and neck cancer treatment have been formulated as peptidomimetics (batimastat, marimastat), nonpeptidic MMPIs (prinomastat, tanomastat, rebimastat), natural MMPIs (silibinin, Neovastat), tetracycline derivatives, and bisphosphonates. ${ }^{74,139,140}$ Marimastat is a widely tested MMPI and the first orally bioavailable MMPI for clinical trials. The effects of marimastat were based on its ability to inhibit the release of major C-ERBB ligands, such as TGF, $\beta$-cellulin, and heregulin. ${ }^{74}$

Nafamostat mesylate (FUT175), a serine protease inhibitor, has been shown to perturb MMP2 and MMP9 activity through the downregulation of TGF $\beta$ in HNSCC. ${ }^{141}$ Treatment with $\alpha$-mangostin in vitro has been shown to decrease MMP2 and MMP9 expression and to inhibit HNSCC growth in a concentration-dependent manner, possibly through a JNK and ERK1/2 signaling pathway. ${ }^{142,143}$ Also, proteasome inhibitors, including ALLN and lactacystin, caused suppression of TNF $\alpha$-induced migration of OSCC cells, via interruption of

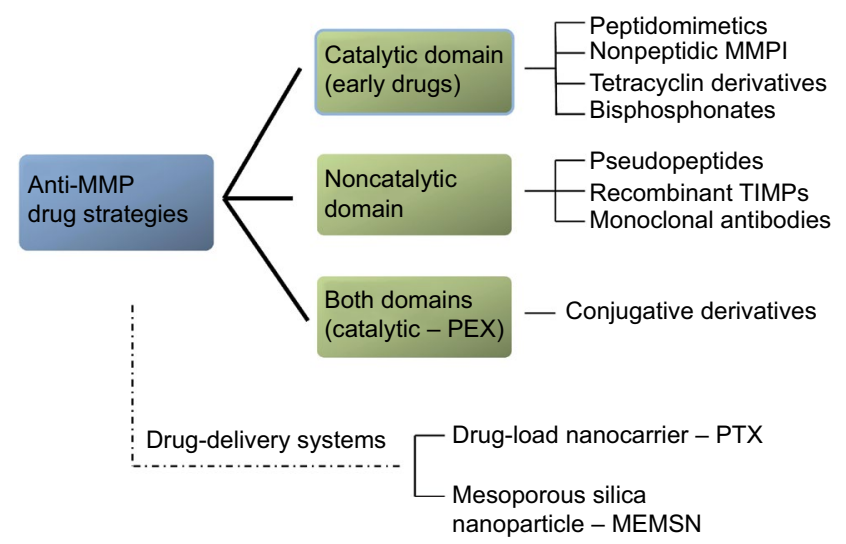

Figure 4 Schematic of drug-therapy strategies against MMPs.

Notes: Anti-MMP drug-design strategies target either catalytic or noncatalytic MMP activity.

Abbreviations: MMP, metalloproteinase; MMPI, MMP inhibitor; PTX, paclitaxel; MEMSN, multifunctional envelope-type mesoporous silica nanoparticle. 
NFKB activation and MMP9 production. ${ }^{144}$ Tranexamic acid and SLPI have been evaluated for their potential to downregulate MMP activity by inhibiting plasminogen activation. ${ }^{145,146}$

\section{Other design strategies targeting the MMP catalytic domain}

Following disappointments with treatment outcomes with earlier anti-MMP regimes, design strategies soon shifted to more sophisticated, selective inhibitors, with fewer side effects. One such strategy focused on designing smallmolecule inhibitors that fit in size and shape with the variable $\mathrm{S1}^{\prime}$ deep cavity of the catalytic domain as an alternative approach to disrupting the strong catalytic zinc-binding activity using MMP12-inhibition models. ${ }^{147,148}$ Pseudopeptides with the general formula X-1-Glu- $\mathrm{NH}_{2}$ that affected zinc ion binding were recognized as MMP12 inhibitors. ${ }^{149}$

More recently, two monoclonal antibodies have been designed to inhibit substrate activation by binding to the catalytic domain without affecting the catalytic zinc region. ${ }^{38}$ The first, DX2400, is a specific inhibitor of MMP14, known to activate pro-MMP2, and promotes angiogenesis, cell invasion, and metastasis in breast cancer cells. ${ }^{150}$ The second antibody, REGA3G12, a murine monoclonal antibody, is designed to inhibit the human MMP9 catalytic domain secreted by neutrophils. ${ }^{151}$ Alternatives to synthetic antibodies have been proposed, namely natural human TIMPs. Paradoxically, TIMP expression is generally increased in OSCC, and is associated with increased metastatic risk and tumor-cell migration. ${ }^{152,153}$ However, recombinant TIMPs are novel promising variants, such as that developed for selective inhibition of MMP14 resulting in decreased MT1MMP activity and CD44 shedding in breast cancer and fibrosarcoma cells. ${ }^{154}$

Currently, doxycycline hyclate (Periostat; Galderma Laboratories LP, Fort Worth, TX, USA) is the only MMPI approved by the US Food and Drug Administration, and is used for the treatment of periodontal diseases. At the moment, it is not clear whether or not doxycycline, an MMP1 inhibitor, possesses chelating activity that targets the catalytic domain or whether it targets the hemopexin-like domain..$^{50,155,156}$ With respect to MMP7, doxycycline is considered to act on hydrophobic tryptophan residues of the catalytic domain proximal to the zinc ion. ${ }^{157}$

\section{Targeting the MMP noncatalytic domain}

Recent recognition of the MMP hemopexin (noncatalytic) region, providing new insights into the functional role and structural homology of MMPs, have spurred a fresh quest for new inhibitors targeting the hemopexin domain. In both in vitro and in vivo systems, designed small molecules and peptides exert their inhibitory effects by preventing dimerization, thereby reducing tumor size, MMP-induced migration, and angiogenesis. ${ }^{158-160}$ Promising studies have shown that these selective compounds could bind on specific sites for each MMP inside their hemopexin domain and prevent dimer-induced functions of several MMPs, including MMP14 and $-9 .{ }^{158-162}$

A more sophisticated approach proposed a bifunctional fusion protein able to bind and inactivate both the catalytic and hemopexin domains of MMP2. ${ }^{163}$ This macromolecular protein was made by conjugation of an MMP2-selective inhibitory peptide (APP-IP) to the N-terminus of TIMP2. ${ }^{163}$ Double binding of this recombinant protein inhibited activation of pro-MMP2 and reduced the degradation of type IV collagen and the migration potential of human fibrosarcoma cells. ${ }^{163}$

Given the desire to target cancer cells specifically with any therapeutic regimen, attention is also being focused on drug-delivery systems for anti-MMP drugs. Liposomes are small vesicles able to conjugate with several compounds, including selective markers or peptides, and transfer them intracellularly. Zhu et al ${ }^{164}$ developed such a drug-load nanocarrier containing paclitaxel (PTX) (conjugate/prodrug, $\mathrm{PEG}_{2,000}$ peptide-PTX) and tested its activity against MMP2. The results were very promising, as the investigators reported high cellular uptake and antitumor efficacy combined with low side toxicity in a non-small-cell lung cancer mouse xenograft model. ${ }^{164}$ Similarly, a multifunctional envelope-type mesoporous silica nanoparticle was developed for selective intracellular drug delivery, containing an RGD motif and an MMP-substrate peptide, Pro-Leu-Gly-Val-Arg. ${ }^{165}$ Treatment of SCC7, HT29, and 293T cells with this drug-delivery system resulted in increased cell death, with low cytotoxic effects. ${ }^{165}$

Taken together, MMPs remain hopeful targets for anticancer therapy in various types of solid and hematological malignancies, in spite of disappointments with earlier regimens. ${ }^{166}$ Therefore, ongoing research continues to explore modern therapeutic approaches combining small molecules and macromolecular inhibitors with novel drug-delivery systems in HNSCCs.

\section{Conclusion}

The prognosis of patients with HNSCC remains dismal, in spite of continuing advances in various modes of therapy. Surgery remains the mainstay of treatment of head and neck cancers. Particularly disappointing is the slow pace in discovering drugs that make for an effective chemothera- 
peutic approach to the treatment of head and neck cancers. The discovery of such drugs will obviate the morbidity and mortality often associated with extensive cancer surgery of the head and neck.

MMPs have well-established complex and key roles in HNSCC. Specific MMPs, including MMP1, -2, -3, -7, -8, -9, $-10,-11,-13$, and -14 , show aberrant expression in cancer tissues, and stand as potential diagnostic and prognostic biomarkers. However, conflicting data and results attributable to finesse and other variabilities associated with experimental procedures and statistical analytic methods confound the results. The heterogeneity of HNSCCs related to specific sites further complicates the interpretation of the biologic significance of expressed molecules, such as MMPs.

Earlier anti-MMP drug designs focused on the catalytic role of MMPs ostensibly responsible for matrix remodeling, angiogenesis, and cancer invasion. However, it is now well known that the structure of MMP-family members includes the hitherto less-emphasized hemopexin-like C-terminal domain, which mediates proteolysis-independent MMP activities in several important physiological and pathological processes. This latter domain now presents itself as an exciting new frontier for MMP cancer research. The noncatalytic functions of MMPs commonly found in head and neck cancers are now well elucidated, as in other system malignancies. This provides the justification to intensify research on potential anti-MMP biomimetic-based targeting of MMP noncatalytic domains. Therefore, MMPs remain a viable target for HNSCC therapy, with the added opportunity to enhance the concept of the personalized medicine approach for effective treatment of HNSCC patients.

\section{Disclosure}

The authors report no conflicts of interest in this work.

\section{References}

1. Jemal A, Bray F, Center MM, Ferlay J, Ward E, Forman D. Global cancer statistics. CA Cancer J Clin. 2011;61(2):69-90.

2. Leemans CR, Braakhuis BJ, Brakenhoff RH. The molecular biology of head and neck cancer. Nat Rev Cancer. 2011;11(1):9-22.

3. Ragin CC, Modugno F, Gollin SM. The epidemiology and risk factors of head and neck cancer: a focus on human papillomavirus. J Dent Res. 2007;86(2):104-114.

4. Molinolo AA, Amornphimoltham P, Squarize CH, Castilho RM, Patel V, Gutkind JS. Dysregulated molecular networks in head and neck carcinogenesis. Oral Oncol. 2009;45(4-5):324-334.

5. Ruzevick J, Olivi A, Westra WH. Metastatic squamous cell carcinoma to the brain: an unrecognized pattern of distant spread in patients with HPV-related head and neck cancer. J Neurooncol. 2013;112(3): 449-454.

6. Gialeli C, Theocharis AD, Karamanos NK. Roles of matrix metalloproteinases in cancer progression and their pharmacological targeting. FEBS J. 2011;278(1):16-27.
7. Shay G, Lynch CC, Fingleton B. Moving targets: emerging roles for MMPs in cancer progression and metastasis. Matrix Biol. 2015; 44-46:200-206.

8. Kessenbrock K, Wang CY, Werb Z. Matrix metalloproteinases in stem cell regulation and cancer. Matrix Biol. 2015;44-46:184-190.

9. Nagase H, Woessner JF Jr. Matrix metalloproteinases. J Biol Chem. 1999;274:21491-21494.

10. Puente XS, Sanchez LM, Overall CM, Lopez-Otin C. Human and mouse proteases: a comparative genomic approach. Nat Rev Genet. 2003;4(7):544-558.

11. Ala-Aho R, Kähäri VM. Collagenases in cancer. Biochimie. 2005; 87(3-4):273-286

12. Syggelos SA, Aletras AJ, Smirlaki I, Skandalis SS. Extracellular matrix degradation and tissue remodeling in periprosthetic loosening and osteolysis: focus on matrix metalloproteinases, their endogenous tissue inhibitors, and the proteasome. Biomed Res Int. 2013;2013:230805.

13. Lee JT, Pamir N, Liu NC, et al. Macrophage metalloelastase (MMP12) regulates adipose tissue expansion, insulin sensitivity, and expression of inducible nitric oxide synthase. Endocrinology. 2014;155(9):3409-3420.

14. Itoh Y. Membrane-type matrix metalloproteinases: their functions and regulations. Matrix Biol. 2015;44-46:207-223.

15. Hiraoka N, Allen E, Apel IJ, Gyetko MR, Weiss SJ. Matrix metalloproteinases regulate neovascularization by acting as pericellular fibrinolysins. Cell. 1998;95(3):365-377.

16. Hotary KB, Yana I, Sabeh F, et al. Matrix metalloproteinases (MMPs) regulate fibrin-invasive activity via MT1-MMP-dependent and -independent processes. J Exp Med. 2002;195(3):295-308.

17. Eckhard U, Huesgen PF, Schilling O, et al. Active site specificity profiling of the matrix metalloproteinase family: proteomic identification of 4300 cleavage sites by nine MMPs explored with structural and synthetic peptide cleavage analyses. Matrix Biol. 2016;49:37-60.

18. Llano E, Pendás AM, Knäuper V, et al. Identification and structural and functional characterization of human enamelysin. J Biol Chem. 1997;36(49):15101-15108.

19. Bartlett JD, Ryu OH, Xue J, Simmer JP, Margolis HC. Enamelysin mRNA displays a developmentally defined pattern of expression and encodes a protein which degrades amelogenin. Connect Tissue Res. 1998;39(1-3):101-109.

20. Begue-Kirn C, Krebsbach PH, Bartlett JD, Butler WT. Dentin sialoprotein, dentin phosphoprotein, enamelysin and ameloblastin: toothspecific molecules that are distinctively expressed during murine dental differentiation. Eur J Oral Sci. 1998;106(5):963-970.

21. Hu Y, Smith CE, Richardson AS, Bartlett JD, Hu JC, Simmer JP. MMP20, KLK4, and MMP20/KLK4 double null mice define roles for matrix proteases during dental enamel formation. Mol Genet Genomic Med. 2015;4(2):178-196.

22. Saxena G, Koli K, de la Garza J, Ogbureke KU. Matrix metalloproteinase 20-dentin sialophosphoprotein interaction in oral cancer. J Dent Res. 2015;94(4):584-593.

23. Koli K, Saxena G, Ogbureke KU. Expression of matrix metalloproteinase (MMP)-20 and potential interaction with dentin sialophosphoprotein (DSPP) in human major salivary glands. $J$ Histochem Cytochem. 2015;63(7):524-533.

24. Ogbureke KU, Koli K, Saxena G. Matrix metalloproteinase 20 coexpression with dentin sialophosphoprotein in human and monkey kidneys. J Histochem Cytochem. 2016;64(10):623-636.

25. Yan C, Boyd DD. Regulation of matrix metalloproteinase gene expression. J Cell Physiol. 2007;211(1):19-26.

26. Koul HK, Pal M, Koul S. Role of p38 MAP kinase signal transduction in solid tumors. Genes Cancer. 2013;4(9-10):342-359.

27. Attard G, Ang JE, Olmos D, de Bono JS. Dissecting prostate carcinogenesis through ETS gene rearrangement studies: implications for anticancer drug development. J Clin Pathol. 2008;61(8):891-896.

28. Huang WC, Sala-Newby GB, Susana A, Johnson JL, Newby AC. Classical macrophage activation up-regulates several matrix metalloproteinases through mitogen activated protein kinases and nuclear factor-кB. PLoS One. 2012;7(8):e42507. 
29. Yao Y, Ma J, Xue Y, et al. MiR-449a exerts tumor-suppressive functions in human glioblastoma by targeting Myc-associated zinc-finger protein. Mol Oncol. 2015;9(3):640-656.

30. Hall MC, Young DA, Waters JG, et al. The comparative role of activator protein 1 and Smad factors in the regulation of TIMP-1 and MMP-1 gene expression by transforming growth factor- $\beta 1$. J Biol Chem. 2003; 278(12):10304-10313.

31. Benderdour M, Tardif G, Pelletier JP, Dupuis M, Geng C, MartelPelletier J. A novel negative regulatory element in the human collagenase-3 proximal promoter region. Biochem Biophys Res Commun. 2002;291(5):1151-1159.

32. Arendt Y, Banci L, Bertini I, et al. Catalytic domain of MMP20 (enamelysin): the NMR structure of a new matrix metalloproteinase. FEBS Lett. 2007;581(24):4723-4726.

33. Garofalo M, Di Leva G, Romano G, et al. miR-221\&222 regulate TRAIL resistance and enhance tumorigenicity through PTEN and TIMP3 downregulation. Cancer Cell. 2009;16(6):498-509.

34. Dufour A, Overall CM. Missing the target: matrix metalloproteinase antitargets in inflammation and cancer. Trends Pharmacol Sci. 2013;34(4):233-242.

35. Murphy G, Nagase H. Progress in matrix metalloproteinase research. Mol Aspects Med. 2008;29(5):290-308.

36. Fedarko NS, Jain A, Karadag A, Fisher LW. Three small integrin binding ligand $\mathrm{N}$-linked glycoproteins (SIBLINGs) bind and activate specific matrix metalloproteinases. FASEB J. 2004;18(6):734-736.

37. Fisher LW, Torchia DA, Fohr B, Young MF, Fedarko NS. Flexible structures of SIBLING proteins, bone sialoprotein, and osteopontin. Biochem Biophys Res Commun. 2001;280(2):460-465.

38. Cathcart J, Pulkoski-Gross A, Cao J. Targeting matrix metalloproteinases in cancer: bringing new life to old ideas. Genes Dis. 2015;2(1):26-34.

39. MiYY, Zhang LF, Zhu LJ. MMP7-181G allele is a low-penetrant risk factor for cancer development in East Asians. DNA Cell Biol. 2012;31(5):772-776.

40. Baltazar-Rodriguez LM, Anaya-Ventura A, Andrade-Soto M, et al. Polymorphism in the matrix metalloproteinase-2 gene promoter is associated with cervical neoplasm risk in Mexican women. Biochem Genet. 2008;46(3-4):137-144.

41. LiY, Sun DL, Duan YN, et al. Association of functional polymorphisms in MMPs genes with gastric cardia adenocarcinoma and esophageal squamous cell carcinoma in high incidence region of north China. Mol Biol Rep. 2010;37(1):197-205.

42. Peng B, Cao L, Ma X, Wang W, Wang D, Yu L. Meta-analysis of association between matrix metalloproteinases 2, 7 and 9 promoter polymorphisms and cancer risk. Mutagenesis. 2010;25(4):371-379.

43. Li X, Qu L, Zhong Y, Zhao Y, Chen H, Daru L. Association between promoters polymorphisms of matrix metalloproteinases and risk of digestive cancers: a meta-analysis. J Cancer Res Clin Oncol. 2013; 139(9):1433-1447.

44. Yang TF, Guo L, Wang Q. Meta-analysis of associations between four polymorphisms in the matrix metalloproteinases gene and gastric cancer risk. Asian Pac J Cancer Prev. 2014;15(3):1263-1267.

45. Yang X, Hu JW, Qiu MT, et al. Association of matrix metalloproteinase-3 $-1171(5 \mathrm{~A}>6 \mathrm{~A})$ polymorphism with cancer risk: a meta-analysis of 41 studies. PLoS One. 2014;9(1):e87562.

46. Rodríguez D, Morrison CJ, Overall CM. Matrix metalloproteinases: what do they not do? New substrates and biological roles identified by murine models and proteomics. Biochim Biophys Acta. 2010; 1803(1):39-54.

47. Wang Y, Sheng S, Zhang J, et al. Elevated maspin expression is associated with better overall survival in esophageal squamous cell carcinoma (ESCC). PLoS One. 2013;8(5):e63581.

48. Saleh A, Stathopoulou MG, Dadé S, et al. Angiogenesis related genes NOS3, CD14, MMP3 and IL4R are associated to VEGF gene expression and circulating levels in healthy adults. BMC Med Genet. 2015;16:90.

49. Iizuka S, Ishimaru N, Kudo Y. Matrix metalloproteinases: the gene expression signatures of head and neck cancer progression. Cancers (Basel). 2014;6(1):396-415.

50. Rosenthal EL, Matrisian LM. Matrix metalloproteases in head and neck cancer. Head Neck. 2006;28(7):639-648.
51. Nagata M, Fujita H, Ida $\mathrm{H}$, et al. Identification of potential biomarkers of lymph node metastasis in oral squamous cell carcinoma by cDNA microarray analysis. Int J Cancer. 2003;106(5):683-689.

52. Chung CH, Parker JS, Karaka G, et al. Molecular classification of head and neck squamous cell carcinomas using patterns of gene expression. Cancer Cell. 2004;5(5):489-500.

53. Ye H, Yu T, Temam S, et al. Transcriptomic dissection of tongue squamous cell carcinoma. BMC Genomics. 2008;9:69.

54. Omar AA, Haglund C, Virolainen S, et al. MMP-7, MMP-8, and MMP-9 in oral and cutaneous squamous cell carcinomas. Oral Surg Oral Med Oral Pathol Oral Radiol. 2015;119(4):459-467.

55. Ogbureke KU, Nikitakis NG, Warburton G, et al. Up-regulation of SIBLING proteins and correlation with cognate MMP expression in oral cancer. Oral Oncol. 2007;43(9):920-932.

56. Yamakoshi Y, Hu JC, Iwata T, Kobayashi K, Fukae M, Simmer JP. Dentin sialophosphoprotein is processed by MMP-2 and MMP-20 in vitro and in vivo. J Biol Chem. 2006;281:38235-38243.

57. Rosenthal EL, McCrory A, Talbert M, Carroll W, Magnuson JS, Peters GE. Expression of proteolytic enzymes in head and neck cancer-associated fibroblasts. Arch Otolaryngol Head Neck Surg. 2004; 130(8):943-947.

58. Lotfi A, Mohammadi G, Tavassoli A, Mousaviagdas M, Chavoshi H, Saniee L. Serum levels of MMP9 and MMP2 in patients with oral squamous cell carcinoma. Asian Pac J Cancer Prev. 2015;16(4): 1327-1330.

59. Tadbir AA, Purshahidi S, Ebrahimi H, et al. Serum level of MMP-3 in patients with oral squamous cell carcinoma: lack of association with clinico-pathological features. Asian Pac J Cancer Prev. 2012; 13(9):4545-4548.

60. Chang PY, Kuo YB, Wu TL, et al. Association and prognostic value of serum inflammation markers in patients with leukoplakia and oral cavity cancer. Clin Chem Lab Med. 2013;51(6):1291-1300.

61. Pereira AC, do Carmo ED, da Silva MA, Rosa LE. Matrix metalloproteinase gene polymorphisms and oral cancer. JClin Exp Dent. 2012;4(5): e297-e301.

62. Chaudhary AK, Singh M, Bharti AC, Asotra K, Sundaram S, Mehrotra R. Genetic polymorphisms of matrix metalloproteinases and their inhibitors in potentially malignant and malignant lesions of the head and neck. J Biomed Sci. 2010;17:10.

63. Chaudhary AK, Pandya S, Mehrotra R, Bharti AC, Jain S, Singh M. Functional polymorphism of the MMP-1 promoter (-1607 1G/2G) in potentially malignant and malignant head and neck lesions in an Indian population. Biomarkers. 2010;15(8):684-692.

64. Vairaktaris E, Vassiliou S, Nkenke E, et al. A metalloproteinase-9 polymorphism which affects its expression is associated with increased risk for oral squamous cell carcinoma. Eur J Surg Oncol. 2008;34(4): 450-455.

65. Wu J, Zhang L, Luo H, Zhu Z, Zhang C, Hou Y. Association of matrix metalloproteinases-9 gene polymorphisms with genetic susceptibility to esophageal squamous cell carcinoma. DNA Cell Biol. 2008; 27(10):553-557.

66. Vairaktaris E, Yapijakis C, Vasiliou S, et al. Association of -1171 promoter polymorphism of matrix metalloproteinase-3 with increased risk for oral cancer. Anticancer Res. 2007;27(6B): 4095-4100.

67. Tu HF, Wu CH, Kao SY, Liu CJ, Liu TY, Lui MT. Functional -1562 C-to-T polymorphism in matrix metalloproteinase-9 (MMP-9) promoter is associated with the risk for oral squamous cell carcinoma in younger male areca users. J Oral Pathol Med. 2007;36(7):409-414.

68. Lin SC, Lo SS, Liu CJ, Chung MY, Huang JW, Chang KW. Functional genotype in matrix metalloproteinases- 2 promoter is a risk factor for oral carcinogenesis. J Oral Pathol Med. 2004;33(7):405-409.

69. Nair RR, Avila H, Ma X, et al. A novel high-throughput screening system identifies a small molecule repressive for matrix metalloproteinase-9 expression. Mol Pharmacol. 2008;73(3):919-929.

70. Bedal KB, Grässel S, Oefner PJ, Reinders J, Reichert TE, Bauer R. Collagen XVI induces expression of MMP9 via modulation of AP-1 transcription factors and facilitates invasion of oral squamous cell carcinoma. PloS One. 2014;9(1):e86777. 
71. Lee EJ, Whang JH, Jeon NK, Kim J. The epidermal growth factor receptor tyrosine kinase inhibitor ZD1839 (Iressa) suppresses proliferation and invasion of human oral squamous carcinoma cells via p53 independent and MMP, uPAR dependent mechanism. Ann N Y Acad Sci. 2007;1095:113-128.

72. Suzuki S, Ishikawa K. Combined inhibition of EMMPRIN and epidermal growth factor receptor prevents the growth and migration of head and neck squamous cell carcinoma cells. Int J Oncol. 2014;44(3):912-917.

73. Chen HJ, Lin CM, Lee CY, et al. Phenethyl isothiocyanate suppresses EGF-stimulated SAS human oral squamous carcinoma cell invasion by targeting EGF receptor signaling. Int J Oncol. 2013;43(2):629-637.

74. O-Charoenrat P, Rhys-Evans P, Eccles S. A synthetic matrix metalloproteinase inhibitor prevents squamous carcinoma cell proliferation by interfering with epidermal growth factor receptor autocrine loops Int J Cancer. 2002;100(5):527-533.

75. Dang D, Yang Y, Li X, et al. Matrix metalloproteinases and TGF $\beta 1$ modulate oral tumor cell matrix. Biochem Biophys Res Comm. 2004; 316(3):937-942

76. Egeblad M, Werb Z. New functions for the matrix metalloproteinases in cancer progression. Nat Rev Cancer. 2002;2(3):161-174.

77. Deryugina EI, Quigley JP. Cell surface remodeling by plasmin: a new function for an old enzyme. J Biomed Biotechnol. 2012;2012:564259.

78. Mohtasham N, Babakoohi S, Shiva A, et al. Immunohistochemical study of p53, Ki-67, MMP-2 and MMP-9 expression at invasive front of squamous cell and verrucous carcinoma in oral cavity. Pathol Res Pract. 2013;209(2):110-114.

79. Zuo JH, Zhu W, Li MY, et al. Activation of EGFR promotes squamous carcinoma SCC10A cell migration and invasion via inducing EMT-like phenotype change and MMP-9-mediated degradation of E-cadherin. J Cell Biochem. 2011;112(9):2508-2517.

80. Bauvois B. New facets of matrix metalloproteinases MMP-2 and MMP-9 as cell surface transducers: outside-in signaling and relationship to tumor progression. Biochim Biophys Acta. 2012;1825(1):29-36.

81. Van Tubergen EA, Banerjee R, Liu M, et al. Inactivation or loss of TTP promotes invasion in head and neck cancer via transcript stabilization and secretion of MMP9, MMP2, and IL-6. Clin Cancer Res. 2013;19(5):1169-1179.

82. Munshi HG, Wu YI, Ariztia EV, Stack MS. Calcium regulation of matrix metalloproteinase-mediated migration in oral squamous cell carcinoma cells. J Biol Chem. 2002;277(44):41480-41488.

83. Singh RD, Haridas N, Patel JB, et al. Matrix metalloproteinases and their inhibitors: correlation with invasion and metastasis in oral cancer. Indian J Clin Biochem. 2010;25(3):250-259.

84. Huang Z, Tan N, Guo W, et al. Overexpression of EMMPRIN isoform 2 is associated with head and neck cancer metastasis. PloS One. 2014;9(4):e91596.

85. Liang X, Yang X, Tang Y, et al. RNAi-mediated downregulation of urokinase plasminogen activator receptor inhibits proliferation, adhesion, migration and invasion in oral cancer cells. Oral Oncol. 2008 44(12):1172-1180.

86. Jimi E, Furuta H, Matsuo K, Tominaga K, Takahashi T, Nakanishi O. The cellular and molecular mechanisms of bone invasion by oral squamous cell carcinoma. Oral Dis. 2011;17(5):462-468.

87. Deraz EM, Kudo Y, Yoshida M, et al. MMP-10/stromelysin-2 promotes invasion of head and neck cancer. PloS One. 2011;6(10):e25438.

88. Chuang JY, Tsai CF, Chang SW, et al. Glial cell line-derived neurotrophic factor induces cell migration in human oral squamous cell carcinoma. Oral Oncol. 2013;49(12):1103-1112.

89. Wang H, Wu Q, Liu Z, et al. Downregulation of FAP suppresses cell proliferation and metastasis through PTEN/PI3K/AKT and Ras-ERK signaling in oral squamous cell carcinoma. Cell Death Dis. 2014;5:e1155.

90. Kessenbrock K, Plaks V, Werb Z. Matrix metalloproteinases: regulators of the tumor microenvironment. Cell. 2010;141(1):52-67.

91. Radisky ES, Radisky DC. Matrix metalloproteinases as breast cancer drivers and therapeutic targets. Front Biosci (Landmark Ed). 2015;20:1144-1163.

92. Sounni NE, Paye A, Host L, Noël A. MT-MMPS as regulators of vessel stability associated with angiogenesis. Front Pharmacol. 2011;2:111.
93. Sil $\mathrm{H}$, Chatterjee $\mathrm{A}$. Integrin alpha-V beta-3-matrix metalloproteinase-2 (MMP-2), cross-talk. J Cancer Ther. 2015;6(9):793-802.

94. Shiomi T, Lemaître V, D’Armiento J, Okada Y. Matrix metalloproteinases, a disintegrin and metalloproteinases, and a disintegrin and metalloproteinases with thrombospondin motifs in non-neoplastic diseases. Pathol Int. 2010;60(7):477-496.

95. Tai YL, Chen LC, Shen TL. Emerging roles of focal adhesion kinase in cancer. Biomed Res Int. 2015;2015:690690.

96. Dey N, Young B, Abramovitz M, et al. Differential activation of Wnt$\beta$-catenin pathway in triple negative breast cancer increases MMP7 in a PTEN dependent manner. PLoS One. 2013;8(10):e77425.

97. Lu H, Yang Z, Zhang H, Gan M, Zhou T, Wang S. The expression and clinical significance of matrix metalloproteinase 7 and tissue inhibitor of matrix metalloproteinases 2 in clear cell renal cell carcinoma. Exp Ther Med. 2013;5(3):890-896.

98. Jimenez L, Jayakar SK, Ow TJ, Segall JE. Mechanisms of invasion in head and neck cancer. Arch Pathol Lab Med. 2015;139(11):1334-1348.

99. Kim JM, Kim HJ, Koo BS, Rha KS, Yoon YH. Expression of matrix metalloproteinase-12 is correlated with extracapsular spread of tumor from nodes with metastasis in head and neck squamous cell carcinoma. Eur Arch Otorhinolaryngol. 2013;270(3):1137-1142.

100. Yu G, Herazo-Maya JD, Nukui T, et al. Matrix metalloproteinase-19 promotes metastatic behavior in vitro and is associated with increased mortality in non-small cell lung cancer. Am J Respir Crit Care Med. 2014;190(7):780-790.

101. Stratman AN, Davis GE. Endothelial cell-pericyte interactions stimulate basement membrane matrix assembly: influence on vascular tube remodeling, maturation, and stabilization. Microsc Microanal. 2012;18(1):68-80.

102. Onimaru M, Yonemitsu Y, Suzuki H, Fujii T, Sueishi K. An autocrine linkage between matrix metalloproteinase-14 and Tie-2 via ectodomain shedding modulates angiopoietin-1-dependent function in endothelial cells. Arterioscler Thromb Vasc Biol. 2010;30(4):818-826.

103. Ugarte-Berzal E, Vandooren J, Bailon E, Opdenakker G, Garcia-Pardo A. 1. Inhibition of MMP-9-dependent degradation of gelatin, but not other MMP-9 substrates, by the MMP-9 hemopexin domain blades 1 and 4. J Biol Chem. 2016;291(22):11751-11760.

104. Kessenbrock K, Wang CY, Werb Z. Matrix metalloproteinases in stem cell regulation and cancer. Matrix Biol. 2015;44-46:184-190.

105. Cha H, Kopetzki E, Huber R, Lanzendörfer M, Brandstetter H. Structural basis of the adaptive molecular recognition by MMP9. J Mol Biol. 2002;320(5):1065-1079.

106. Piccard H, Van den Steen PE, Opdenakker G. Hemopexin domains as multifunctional liganding modules in matrix metalloproteinases and other proteins. J Leukoc Biol. 2007;81(4):870-892.

107. Redondo-Muñoz J, Ugarte-Berzal E, Garcia-Marco JA, et al. $\alpha 4 \beta 1$ Integrin and 190-kDa CD44v constitute a cell surface docking complex for gelatinase B/MMP-9 in chronic leukemic but not in normal B cells. Blood. 2008;112(1):169-178.

108. Hahn-Dantona E, Ruiz JF, Bornstein P, Strickland DK. The low density lipoprotein receptor-related protein modulates levels of matrix metalloproteinase 9 (MMP-9) by mediating its cellular catabolism. J Biol Chem. 2001;276(18):15498-15503.

109. Van den Steen PE, Van Aelst I, Hvidberg V, et al. The hemopexin and O-glycosylated domains tune gelatinase B/MMP-9 bioavailability via inhibition and binding to cargo receptors. J Biol Chem. 2006; 281(27):18626-18637.

110. Goldberg GI, Strongin A, Collier IE, et al. Interaction of 92-kDa type IV collagenase with the tissue inhibitor of metalloproteinases prevents dimerization, complex formation with interstitial collagenase, and activation of the proenzyme with stromelysin. J Biol Chem. 1992;267(7):4583-4591.

111. Butler GS, Apte SS, Willenbrock F, Murphy G. Human tissue inhibitor of metalloproteinases 3 interacts with both the $\mathrm{N}$ - and $\mathrm{C}$-terminal domains of gelatinases $\mathrm{A}$ and $\mathrm{B}$ : regulation by polyanions. $J$ Biol Chem. 1999;274(16):10846-10851.

112. Burg-Roderfeld M, Roderfeld M, Wagner S, Henkel C, Grötzinger J, Roeb E. MMP-9-hemopexin domain hampers adhesion and migration of colorectal cancer cells. Int J Oncol. 2007;30(4):985-992. 
113. Roeb E, Schleinkofer K, Kernebeck T, et al. The matrix metalloproteinase 9 (MMP-9) hemopexin domain is a novel gelatin binding domain and acts as an antagonist. J Biol Chem. 2002;277(52):50326-50332.

114. Ugarte-Berzal E, Bailón E, Amigo-Jiménez I, et al. A 17-residue sequence from the matrix metalloproteinase-9 (MMP-9) hemopexin domain binds $\alpha 4 \beta 1$ integrin and inhibits MMP-9-induced functions in chronic lymphocytic leukemia B cells. J Biol Chem. 2012;287(33):27601-27613.

115. Ugarte-Berzal E, Bailón E, Amigo-Jiménez I, Albar JP, García-Marco JA, García-Pardo A. A novel CD44-binding peptide from the promatrix metalloproteinase-9 hemopexin domain impairs adhesion and migration of chronic lymphocytic leukemia (CLL) cells. J Biol Chem. 2014;289(22):15340-15349.

116. Paupert J, Mansat-De Mas V, Demur C, Salles B, Muller C. Cell-surface MMP-9 regulates the invasive capacity of leukemia blast cells with monocytic features. Cell Cycle. 2008;7(8):1047-1053.

117. Dufour A, Sampson NS, Zucker S, Cao J. Role of the hemopexin domain of matrix metalloproteinases in cell migration. J Cell Physiol. 2008;217(3):643-651.

118. Radjabi AR, Sawada K, Jagadeeswaran S, et al. Thrombin induces tumor invasion through the induction and association of matrix metalloproteinase-9 and $\beta 1$-integrin on the cell surface. J Biol Chem. 2008;283(5):2822-2834.

119. Ardi VC, Van den Steen PE, Opdenakker G, Schweighofer B, Deryugina EI, Quigley JP. Neutrophil MMP-9 proenzyme, unencumbered by TIMP-1, undergoes efficient activation in vivo and catalytically induces angiogenesis via a basic fibroblast growth factor (FGF-2)/ FGFR-2 pathway. J Biol Chem. 2009;284(38):25854-25866.

120. Suenaga N, Mori H, Itoh Y, Seiki M. CD44 binding through the hemopexin-like domain is critical for its shedding by membrane-type 1 matrix metalloproteinase. Oncogene. 2005;24(5):859-868.

121. Eisenach PA, Roghi C, Fogarasi M, Murphy G, English WR. MT1MMP regulates VEGF-A expression through a complex with VEGFR-2 and Src. J Cell Sci. 2010;123(Pt 23):4182-4193.

122. Zarrabi K, Dufour A, Li J, et al. Inhibition of matrix metalloproteinase 14 (MMP-14)-mediated cancer cell migration. J Biol Chem. 2011;286(38):33167-33177.

123. Correia AL, Mori H, Chen EI, Schmitt FC, Bissell MJ. The hemopexin domain of MMP3 is responsible for mammary epithelial invasion and morphogenesis through extracellular interaction with HSP90beta. Genes Dev. 2013;27(7):805-817.

124. Song X, Wang X, Zhuo W, et al. The regulatory mechanism of extracellular Hsp90 $\alpha$ on matrix metalloproteinase-2 processing and tumor angiogenesis. J Biol Chem. 2010;285(51):40039-40049.

125. Galea CA, Nguyen HM, Chandy KG, Smith BJ, Norton RS. Domain structure and function of matrix metalloprotease 23 (MMP23): role in potassium channel trafficking. Cell Mol Life Sci. 2014;71(7):1191-1210.

126. Wiegand S, Dünne AA, Müller HH, et al. Metaanalysis of the significance of matrix metalloproteinases for lymph node disease in patients with head and neck squamous cell carcinoma. Cancer. 2005;104(1):94-100.

127. Liu RR, Li MD, Li T, Tan Y, Zhang M, Chen JC. Matrix metalloproteinase 2 (MMP2) protein expression and laryngeal cancer prognosis: a meta analysis. Int J Clin Exp Med. 2015;8(2):2261-2266.

128. Zhang L, Xi RX, Zhang XZ. Matrix metalloproteinase variants associated with risk and clinical outcome of esophageal cancer. Genet $\mathrm{Mol}$ Res. 2015;14(2):4616-4624.

129. Virós D, Camacho M, Zarraonandia I, et al. Prognostic role of MMP-9 expression in head and neck carcinoma patients treated with radiotherapy or chemoradiotherapy. Oral Oncol. 2013;49(4):322-325.

130. Ogbureke KU, Weinberger PM, Looney SW, Li L, Fisher LW. Expressions of matrix metalloproteinase-9 (MMP-9), dentin sialophosphoprotein (DSPP), and osteopontin (OPN) at histologically negative surgical margins may predict recurrence of oral squamous cell carcinoma. Oncotarget. 2012;3(3):286-298.

131. Fraga CA, Farias LC, de Oliveira MV, et al. Increased VEGFR2 and MMP9 protein levels are associated with epithelial dysplasia grading. Pathol Res Pract. 2014;210(12):959-964.
132. Smith J, Rattay T, McConkey C, Helliwell T, Mehanna H. Biomarkers in dysplasia of the oral cavity: a systematic review. Oral Oncol. 2009;45(8):647-653.

133. Zhou JH, Zhang B, Kernstine KH, Zhong L. Autoantibodies against MMP-7 as a novel diagnostic biomarker in esophageal squamous cell carcinoma. World J Gastroenterol. 2011;17(10):1373-1378.

134. Ding H, Zhu Y, Chu T, Wang S. Epidermal growth factor induces FoxO1 nuclear exclusion to activate MMP7-mediated metastasis of larynx carcinoma. Tumour Biol. 2014;35(10):9987-9992.

135. de Vicente JC, Lequerica-Fernandez P, Santamaria J, Fresno MF. Expression of MMP-7 and MT1-MMP in oral squamous cell carcinoma as predictive indicator for tumor invasion and prognosis. $J$ Oral Pathol Med. 2007;36(7):415-424.

136. Mäkinen LK, Häyry V, Atula T, et al. Prognostic significance of matrix metalloproteinase-2, $-8,-9$, and -13 in oral tongue cancer. J Oral Pathol Med. 2012;41(5):394-399.

137. Korpi JT, Kervinen V, Mäklin H, et al. Collagenase-2 (matrix metalloproteinase-8) plays a protective role in tongue cancer. Br J Cancer. 2008;98(4):766-775.

138. Luukkaa M, Vihinen $\mathrm{P}$, Kronqvist $\mathrm{P}$, et al. Association between high collagenase-3 expression levels and poor prognosis in patients with head and neck cancer. Head Neck. 2006;28(3):225-234.

139. Fisher JF, Mobashery S. Recent advances in MMP inhibitor design. Cancer Metastasis Rev. 2006;25(1):115-136.

140. Shankar P, Kumar R, Singh DK, et al. Published database mining for MMP-3 inhibitors (natural and synthetic). World J Pharm Pharm Sci. 2015:4(10):1629-1637.

141. Yamashita Y, Ishiguro Y, Sano D, et al. Antitumor effects of nafamostat mesilate on head and neck squamous cell carcinoma. Auris Nasus Larynx. 2007;34(4):487-491.

142. Hung SH, Shen KH, Wu CH, Liu CL, Shih YW. $\alpha$-Mangostin suppresses PC-3 human prostate carcinoma cell metastasis by inhibiting matrix metalloproteinase-2/9 and urokinase-plasminogen expression through the JNK signaling pathway. J Agric Food Chem. 2009;57(4):1291-1298.

143. Shih YW, Chien ST, Chen PS, Lee JH, Wu SH, Yin LT. $\alpha$-Mangostin suppresses phorbol 12-myristate 13-acetate-induced MMP-2/MMP-9 expressions via $\alpha v \beta 3$ integrin/FAK/ERK and NF- $\kappa B$ signaling pathway in human lung adenocarcinoma A549 cells. Cell Biochem Biophys. 2010;58(1):31-44.

144. Ikebe T, Takeuchi H, Jimi E, Beppu M, Shinohara M, Shirasuna K. Involvement of proteasomes in migration and matrix metalloproteinase-9 production of oral squamous cell carcinoma. Int J Cancer. 1998;77(4):578-585.

145. Suojanen J, Sorsa T, Salo T. Tranexamic acid can inhibit tongue squamous cell carcinoma invasion in vitro. Oral Dis. 2009;15(2): $170-175$.

146. Wen J, Nikitakis NG, Chaisuparat R, et al. Secretory leukocyte protease inhibitor (SLPI) expression and tumor invasion in oral squamous cell carcinoma. Am J Pathol. 2011;178(6):2866-2878.

147. Devel L, Czarny B, Beau F, Georgiadis D, Stura E, Dive V. Third generation of matrix metalloprotease inhibitors: gain in selectivity by targeting the depth of the S1' cavity. Biochimie. 2010;92(11):1501-1518.

148. Jacobsen JA, Jourden JL, Miller MT, Cohen SM. To bind zinc or not to bind zinc: an examination of innovative approaches to improved metalloproteinase inhibition. Biochim Biophys Acta. 2010;1803(1): 72-94.

149. Czarny B, Stura EA, Devel L, et al. Molecular determinants of a selective matrix metalloprotease-12 inhibitor: insights from crystallography and thermodynamic studies. J Med Chem. 2013;56(3): 1149-1159.

150. Devy L, Huang L, Naa L, et al. Selective inhibition of matrix metalloproteinase-14 blocks tumor growth, invasion, and angiogenesis. Cancer Res. 2009;69(4):1517-1526.

151. Zhou N, Paemen L, Opdenakker G, Froyen G. Cloning and expression in Escherichia coli of a human gelatinase B-inhibitory singlechain immunoglobulin variable fragment (scFv). FEBS Lett. 1997; 414(3):562-566 
152. García MP, Suárez-Peñaranda JM, Gayoso-Diz P, Barros-Angueira F, Gándara-Rey JM, García-García A. Tissue inhibitor of metalloproteinases in oral squamous cell carcinomas: a therapeutic target? Cancer Lett. 2012;323(1):11-19.

153. Niu J, Huang Y, Zhang L. CXCR4 silencing inhibits invasion and migration of human laryngeal cancer Hep-2 cells. Int J Clin Exp Pathol. 2015;8(6):6255-6261.

154. Lee MH, Atkinson S, Rapti M, et al. The activity of a designer tissue inhibitor of metalloproteinases (TIMP)-1 against native membrane type 1 matrix metalloproteinase (MT1-MMP) in a cell-based environment. Cancer Lett. 2010;290(1):114-122.

155. Smith GN Jr, Mickler EA, Hasty KA, Brandt KD. Specificity of inhibition of matrix metalloproteinase activity by doxycycline: relationship to structure of the enzyme. Arthritis Rheum. 1999;42(6):1140-1146.

156. Griffin MO, Fricovsky E, Ceballos G, Villarreal F. Tetracyclines a pleitropic [sic] family of compounds with promising therapeutic properties - review of the literature. Am J Physiol Cell Physiol. 2010;299(3):C539-C548.

157. García RA, Pantazatos DP, Gessner CR, Go KV, Woods VL, Villarreal FJ. Molecular interactions between matrilysin and the matrix metalloproteinase inhibitor doxycycline investigated by deuterium exchange mass spectrometry. Mol Pharmacol. 2005;67(4):1128-1136.

158. Dufour A, Zucker S, Sampson NS, Kuscu C, Cao J. Role of matrix metalloproteinase-9 dimers in cell migration: design of inhibitory peptides. J Biol Chem. 2010;285(46):35944-3556.

159. Dufour A, Sampson NS, Li J, et al. Small-molecule anticancer compounds selectively target the hemopexin domain of matrix metalloproteinase-9. Cancer Res. 2011;71(14):4977-4988.
160. Remacle AG, Golubkov VS, Shiryaev SA, et al. Novel MT1MMP small-molecule inhibitors based on insights into hemopexin domain function in tumor growth. Cancer Res. 2012;72(9): 2339-2349.

161. Lichte A, Kolkenbrock H, Tschesche $H$. The recombinant catalytic domain of membrane-type matrix metalloproteinase-1 (MT1-MMP) induces activation of progelatinase $\mathrm{A}$ and progelatinase A complexed with TIMP-2. FEBS Lett. 1996;397(2):277-282.

162. Mori H, Tomari T, Koshikawa N, et al. CD44 directs membrane-type 1 matrix metalloproteinase to lamellipodia by associating with its hemopexin-like domain. EMBO J. 2002;21(15):3949-3959.

163. Higashi S, Hirose T, Takeuchi T, Miyazaki K. Molecular design of a highly selective and strong protein inhibitor against matrix metalloproteinase-2 (MMP-2). J Biol Chem. 2013;288(13):9066-9076.

164. Zhu L, Wang T, Perche F, Taigind A, Torchilin VP. Enhanced anticancer activity of nanopreparation containing an MMP2-sensitive PEG-drug conjugate and cell-penetrating moiety. Proc Natl Acad Sci U S A. 2013;110(42):17047-17052.

165. Zhang J, Yuan ZF, Wang Y, et al. Multifunctional envelope-type mesoporous silica nanoparticles for tumor-triggered targeting drug delivery. J Am Chem Soc. 2013;135(13):5068-5073.

166. Chaudhary AK, Pandya S, Ghosh K, Nadkarni A. Matrix metalloproteinase and its drug targets therapy in solid and hematological malignancies: an overview. Mutat Res. 2013;753(1):7-23.

167. Eighth International Conference on the Chemistry and Biology of Mineralized Tissues. Proceedings of the 8th ICCBMT. Banff, Alberta, Canada. 2005. ICCBMT: https://iccbmt.mpikg.mpg.de/. Accessed March 20, 2017.
Metalloproteinases In Medicine

\section{Publish your work in this journal}

Metalloproteinases In Medicine is an international, peer reviewed, open access journal that aims to provide a platform for the discussion and dissemination of knowledge about the role that metalloproteinases - such as matrix metalloproteinases (MMP), ADAMs, ADAMTSs, and astacins, as well as their inhibitors - play in diseases.

\section{Dovepress}

The manuscript management system is completely online and includes a very quick and fair peer review system, which is all easy to use. Visit http://www.dovepress.com/testimonials.php to read real quotes from published authors. 